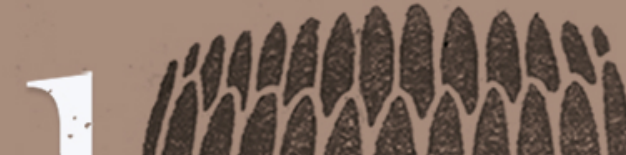

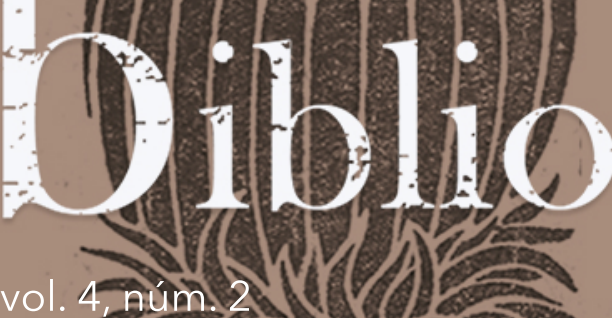

vol. 4, Aum?2

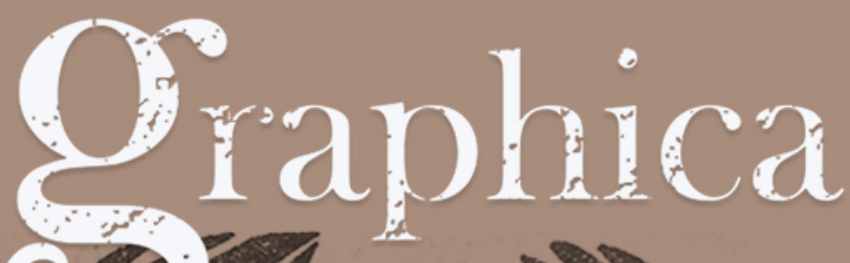

segubdo-semestre 2021 s.

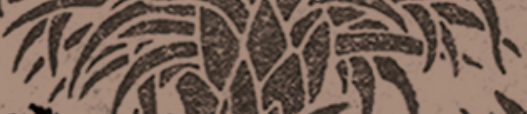
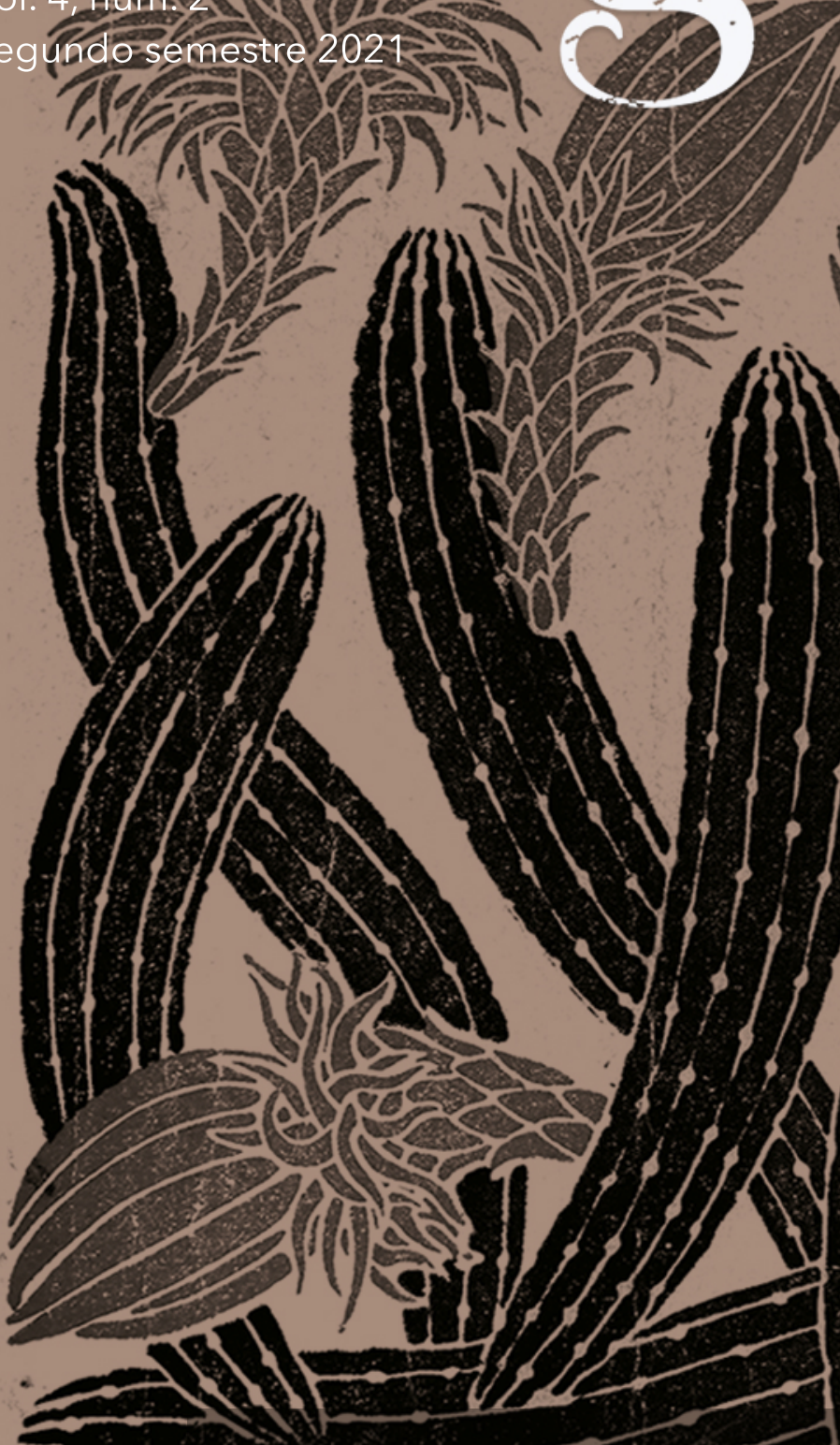

ISSN $2594-178 X$
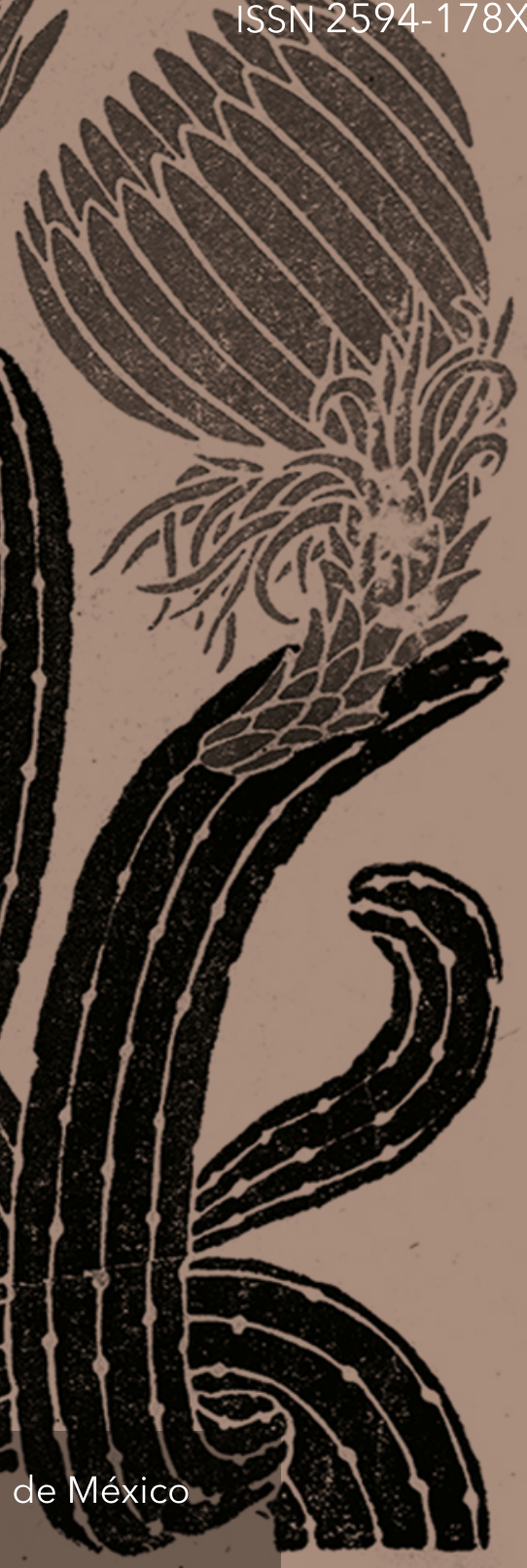


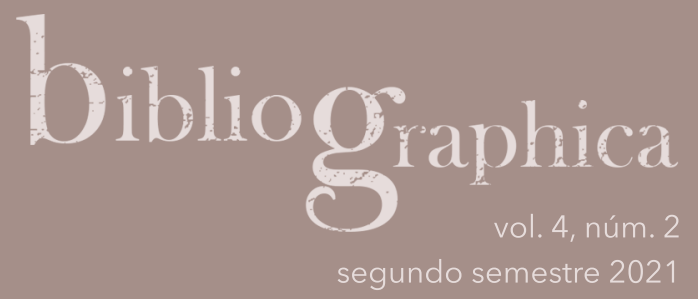

\section{La publicación periódica científica en el núcleo: bases para el desarrollo de modelos}

Scientific Periodical Publications at the Core:

Basis for the Development of Models

\section{Dalia Valdez Garza}

Universidad Nacional Autónoma de México,

Instituto de Investigaciones Bibliográficas,

Ciudad de México. México

daliavg@unam.mx

ORCID: https://orcid.org/0000-0001-7739-6988

Recepción: 26.02.2021 / Aceptación: 27.07.2021

DoI: https://doi.org/10.22201/iib.2594178xe.2021.2.102 
Resumen

Palabras clave

Abstract

Keywords
Este artículo contiene fundamentos para elaborar modelos de estudio centrados en la publicación periódica científica, con perspectiva histórica e interdisciplinaria, desde la visión integral de la historia del libro. Las aportaciones actuales subordinan el sistema editorial al científico, ambos engranados al "sistema documental y de información", y desarticulados de un "sistema hemerográfico" global. Se contextualiza la actividad de publicación en la ciencia, sus actores y las fronteras de sus funciones en un sistema y en otro, pero siempre en interacción e interdependencia. Esta visión integral permite superar limitaciones que daban primacía a los "textos científicos" y a sus autores. El ecosistema de la publicación periódica científica se propone como base para el desarrollo de modelos de estudio en los sistemas propuestos, extensiones donde se explica su dinámica interna particular, y quiénes y cómo intervienen. Esta exploración teóricometodológica surgió al desarrollar un "modelo de edición" para investigar el Boletín de Ciencias Médicas (México, 1910-1916).

Publicación periódica científica; modelos; historia del libro; ecosistema de la publicación periódica científica; edición de publicaciones periódicas científicas.

This article contains the fundamentals to elaborate study models centered in the scientific periodical publication, with a historical and interdisciplinary viewpoint, from the integral perspective of book studies. Current contributions have placed the editorial system as a subordinate to the scientific one, both of which are geared to the "documentary and information system", and disjointed in their study to a global "hemerographic system". This paper undertakes the explanation and contextualization of the activities of science publication, its actors and their funtions' boundaries in said systems- always maintaining a relation of interaction and dependence. This comprehensive vision of the scientific periodical publication allows us to overcome the limitations that gave primacy or only acknowledged "scientific texts" and their authors. Thus, the scientific periodical publication ecosystem is presented here as a basis for developing particular study models in the proposed systems, extensions that explain its particular internal dynamics, and who intervenes and how. An example of this is the "editorial model" that has been the starting point for this exploration, the research of the Boletín de Ciencias Médicas (Mexico, 1910-1916).

Scientific periodical publication; models; book history; scientific periodical publication ecosystem; science periodical publishing. 


\section{Introducción}

\section{El germen de un método}

Mi incursión en el estudio de las publicaciones periódicas científicas de México inició en 2009 con la Gazeta de Literatura de México de José Antonio Alzate (Ozumba, 1737 - Ciudad de México, 1799), cuarta y última de las obras periódicas de este ilustrado novohispano, editada de 1788 a 1795.' Desde entonces mi perspectiva disciplinaria ha sido la historia del libro y de la edición que toma elementos principalmente de la literatura, la bibliografía y la propia historia. Aunque dentro de la misma disciplina hay distintas corrientes y formas de abordar el estudio del libro, mi interés fue ofrecer lo que Robert Darnton llama la "biografía de un libro", en este caso, de una publicación periódica novohispana. Darnton propone el modelo del "circuito de comunicación"2 para indagar cómo ese producto llamado "libro" llegó a convertirse en lo que es, a partir de la consideración de las personas involucradas, que van desde el autor hasta el lector, con todos sus intermediarios como el impresor, encuadernador, librero, etc., elementos que están planteados acorde con las circunstancias del periodo de producción manual o artesanal. ${ }^{3}$ La propuesta de Darnton fue útil para el caso de estudio de una publicación periódica y para elaborar su biografía, porque en dicha etapa de la producción de impresos se aplicaba la misma tecnología en la elaboración de productos periódicos y no periódicos, aunque en lo que sí se distinguían unos de otros es en los modos de venta y distribución, como entonces quedó planteado.

Más adelante realicé una investigación sobre el Boletín de Ciencias Médicas, revista de medicina publicada en México de 1910 a 1916, creación del médico militar Manuel Saturnino Soriano (Ciudad de México, 1837-1927). Con el mismo objetivo de elaborar una biografía editorial, algunas de las cuestiones

\footnotetext{
${ }^{1}$ Publicada en las dos obras siguientes: Libros y lectores en la Gazeta de Literatura de México (1788-1795) de José Antonio Alzate (México: Bonilla Artigas Editores / ITESM, 2014) y La Gazeta de Literatura de México (1788-1795) como periódico libro. Estudio bibliográfico (Ciudad de México: UNAM, IIB, BNM, HNM / ITESM / Historiadores de las Ciencias y las Humanidades, A. C., 2020).

2 Robert Darnton, "What Is the History of Books?", Daedalus 111, núm. 3, Representations and Realities (verano de 1982): 65-83, acceso el 27 de marzo de 2021, http://www.jstor. org/stable/20024803.

3 "fabricación del papel a mano, composición manual, impresión también pliego a pliego", Fermín de los Reyes Gómez, "El libro moderno desde la bibliografía material y la biblioteconomía", Ayer 58, núm. 2 (2005): 41.
} 
sobre las que se pretendía indagar en este caso eran las siguientes: las funciones de cada miembro del equipo editorial; la dinámica de edición de la publicación que generó un producto impreso con una línea editorial más o menos definida y siempre maleable, lo cual implica un conocimiento de las necesidades de los lectores; la composición interna o elementos paratextuales en cada tomo, desde lo formal; su base de financiamiento (suscripción/publicidad) y los modos de entrega a los compradores; las estrategias de difusión y la diversidad de géneros textuales, entre otras. Pero, en términos metodológicos, ¿cómo obtener ahora esta información y analizarla con una publicación periódica producida más de un siglo después?

El salto de temporalidad de un objeto de estudio del siglo XVIII -como el de mi primera investigación- hacia uno del XX me obligó a buscar nuevas herramientas de análisis, pues simplemente en la segunda, con un material contemporáneo, no encajaba el modelo de Darton, adecuado principalmente para el tratamiento del libro antiguo. Al no encontrarlo, decidí que avanzaría en dos rutas de investigación, la primera que desembocaría en una biografía editorial del Boletín de Ciencias Médicas y a la par una segunda sobre el tema de la edición científica que me permitiera desarrollar un modelo para su estudio.

Se trataba de buscar elementos teóricos y conceptuales que me permitieran, a corto plazo, la construcción de un modelo de edición tentativo para el estudio de una publicación periódica científica (y a largo plazo su comprobación). ${ }^{4}$ De este modo, presento aquí el resultado de esa segunda ruta de indagación, al que se adicionan breves comentarios sobre el Boletín de Ciencias Médicas simplemente para ilustrar acerca del tipo de información generada, producto del modelo, pues no es el objetivo aquí profundizar en ello ni es este un estudio de caso de dicha publicación periódica. Es importante aclarar que el modelo se habría desarrollado, se tratara de esta publicación periódica o de otra, de tal modo que la información particular sobre el Boletín se podrá consultar en su biografía editorial. ${ }^{5}$ Se presentan entonces los fundamentos

\footnotetext{
${ }^{4}$ Mi siguiente proyecto, "La edición de revistas médicas mexicanas (1910-1970)", aunque me brindó la oportunidad de corroborar el modelo ante la revisión de 119 revistas, tiene la limitación de considerar una sola disciplina. Decidí entonces dar el paso a una investigación que considerara publicaciones periódicas científicas representativas de todas las áreas del conocimiento con el proyecto "Modelo histórico para el análisis del proceso de edición de publicaciones periódicas científicas mexicanas (1900-1995)" (Fondo Sectorial de Investigación para la Educación, SEP-Conacyt), en curso.

${ }^{5}$ Se espera que sea publicada por el Instituto de Investigaciones Bibliográficas de la UNAM. Asimismo, pueden consultarse los índices del Boletín de Ciencias Médicas, como parte del
} 
para el diseño de modelos que sirvan para estudiar la publicación periódica científica desde una o varias perspectivas disciplinarias, a partir de un ecosistema que va mucho más allá de la edición, y que sostiene una visión integral de este objeto de estudio a partir de la historia del libro.

\section{La historia del libro y de la edición}

En el estudio de las publicaciones periódicas científicas de México han prevalecido las perspectivas de estudio de la historia de la ciencia e historia de la prensa. En ambas, por sus intereses propios, se ha ido en busca de los contenidos de estos materiales y ese es quizá el punto principal que las diferencia de la historia del libro. ${ }^{\circ}$ Se sabe que en la historia del libro referirse al "libro" es una forma genérica correspondiente a aquellos productos de la misma clase o especie que son resultado de un proceso de edición y que se reproducen a través de algún tipo de tecnología. ${ }^{7}$ El Boletín de Ciencias Médicas es una publicación periódica impresa que hoy se clasifica como "revista". Leslie Howsam propone que el libro es a la vez "texto escrito, objeto material y transacción cultural", ${ }^{8}$ y sugiere entenderlo más que como una categoría, como un proceso, ya que "los libros suceden; le suceden a la gente que los lee, reproduce, difunde y compone, y resultan ser significativos". 9 Así el Boletín de Ciencias Médicas, en su calidad de libro desde esta disciplina, con sus rasgos particulares más evidentes que son su

Sistema de Índices de la Hemeroteca Nacional de México (Sihena), en la página https:// sihena.iib.unam. $\mathrm{mx} /$, un recurso de suma utilidad para los investigadores, pues da acceso a información de referencia sobre los contenidos de diversas publicaciones, como ésta.

${ }^{6}$ En los ámbitos anglosajón y francófono se ha explorado la conjunción de la "historia de la ciencia" y la "historia del libro y de la edición", de lo que son muestra respectivamente Marina Frasca-Spada y Nick Jardine, eds., Books and the Sciences in History (Cambridge, UK: Cambridge University Press, 2000) y Franck Jovanovic, Viera Rebolledo-Dhuin y Norbert Verdier, "Histoire des sciences et histoire de l'édition: de quelle manière peuvent-elles se compléter?", Philosophia Scientiæ 22, núm. 1 (2018): 3-22, acceso el 27 de marzo de 2021, http://journals.openedition.org/.

${ }^{7}$ No se entrará en la discusión de si se consideran también en la disciplina los libros como objetos de arte que pueden fabricarse de manera única, ya que pertenecen a otro circuito de difusión y a otra intencionalidad.

8 "a written text, a material object, and a cultural transaction", Leslie Howsam, Old Books \& New Histories: An Orientation to Studies in Book and Print Culture (Toronto: University of Toronto Press, 2006), vii. Traducción propia.

9 "books happen; they happen to people who read, reproduce, disseminate, and compose them; and they happen to be significant", ibid., 5. Traducción propia. 
condición periódica y su temática médica, y a partir de lo que indica Howsam, se estudió desde las siguientes consideraciones generales.

El Boletín de Ciencias Médicas tenía como público objetivo quienes integraban la comunidad de médicos, dentistas y veterinarios, nacionales y extranjeros, con requerimientos específicos: un conocimiento especializado, de actualización y rápida difusión, así como noticias y avisos de las actividades relacionadas con la práctica profesional, la academia y sociabilidades médicas. Fue un órgano de difusión del conocimiento y de noticias para la comunidad médica en un tiempo en que el conflicto armado hacía no sólo útil, sino urgente que cumpliera con su objetivo, como lo es para las revistas científicas actualmente con la pandemia de covid-19. Por ejemplo, se requería combatir las consecuencias de las condiciones de insalubridad que podrían generarse por la guerra (epidemias) y brindar la mejor atención posible a los heridos. No obstante, esto no es suficiente para entender su continuidad y persistencia.

En la biografía editorial de esta publicación periódica se analiza cuáles fueron las estrategias que permitieron al médico-editor Manuel S. Soriano sostenerla mientras transcurría la Revolución mexicana, es decir, si tuvo que hacer adecuaciones en su línea editorial a lo largo del tiempo, si incorporaba cambios a partir de los intereses de los lectores, y otras posibles acciones de supervivencia ante condiciones tan adversas de crisis y carestía que en el "año cero"10 la socavaron. Es muy probable que la experiencia de Soriano en el periodismo médico durante el siglo XIX, y las herramientas adquiridas en este ejercicio, principalmente como administrador, posibilitaran la permanencia de su último proyecto editorial durante casi seis años. El médico-editor publica en diciembre de 1915 un texto en memoria de los "doctores", quienes enseñaron que "todo se debe sacrificar por la patria y la humanidad", en alusión a los que habían fallecido víctimas de tifo, y ahí justamente menciona que su Boletín es el único que en ese momento se publica en la República. ${ }^{11}$

\footnotetext{
10 Para una revisión de este contexto véanse, de Ariel Rodríguez Kuri, "El año cero: el Ayuntamiento de México y las facciones revolucionarias (agosto 1914 - agosto 1915)", en Ciudad de México: Instituciones, actores sociales y conflicto político, 1774-1931, comp. de Carlos Illades y Ariel Rodríguez Kuri (México: El Colegio de Michoacán / UAM, 1996), 191-220; e Historia del desasosiego. La Revolución en la Ciudad de México, 1911-1922 (México: El Colegio de México, 2010).

${ }^{11}$ Manuel S. Soriano, "A la grata memoria de los Doctores", Boletín de Ciencias Médicas 6, núm. 6 (diciembre de 1915): 161.
} 


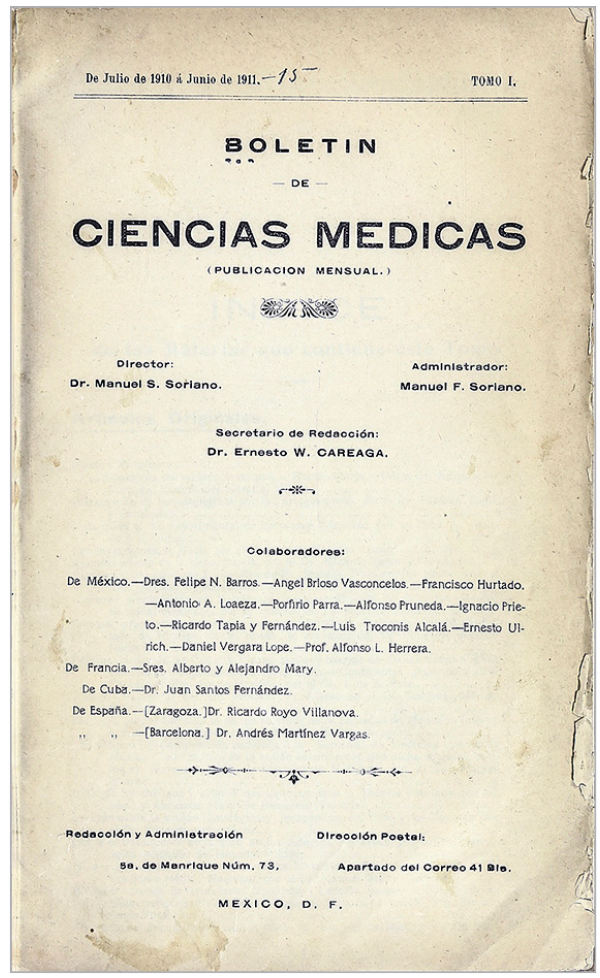

Pero el Boletín de Ciencias Médicas es también un producto de la imprenta mecánica, lo que impacta en sus características tipográficas (puesta en página), estructurales internas (paratextos) y externas (números reunidos en tomos encuadernados). Resultado de un perfil editorial muy bien definido por su director, refleja la cultura científica y de los profesionales de la medicina de su momento que cumplió con la necesidad de actualización constante. Su biografía editorial revela la idea de libro como proceso que ocurre no sólo durante el acto creativo de su diseño y fabricación, sino en su recepción y uso, es decir, con las mediaciones que se establecieron para convertir los textos manuscritos en un producto tipográfico con una estética y funcionalidad cuya experiencia produjo ciertos significados para aquellos lectores.

Estudiar las publicaciones periódicas científicas con atención a la vez en sus contenidos, materia y como transacción cultural, como se hace en historia del libro, permite identificar las actividades relacionadas con la escritura, edi- 
ción, reproducción y lectura que participan en su proceso y en su "suceder". Escuchar, en el análisis del libro, las voces de sus hacedores, en sus distintos momentos y niveles de intervención, implica hacer diseños metodológicos que las hagan audibles en ese concierto. En este sentido, Emmanuël Souchier habla de una "enunciación editorial". ${ }^{12}$

Esta perspectiva demanda al investigador un método de estudio que permita que un libro se revele como un objeto capaz de contar su propia historia mediante la interpretación de sus diversos tipos de lenguajes como el verbal, iconográfico y tipográfico, a los que agregaría las expresiones de su "fisicalidad" (ergonomía, componentes químicos de sus materiales...) o de su "virtualidad". De esta forma pueden construirse perfiles de quienes participan en estas labores y ahondar en el estudio de sus prácticas y códigos. También es posible profundizar en el análisis de las condiciones en que fueron elaborados, por ejemplo los modos de la tecnología de reproducción y difusión de estos productos; la legislación que rige y define sus características y posibilidades de transmisión, así como aspectos sociales y culturales que plantean escenarios para la detección de una necesidad lectora concretada en un producto editorial. Todo en conjunto define la idea de la generación de un producto para que sus características colaboren en la mejor experiencia de lectura que se pueda tener a partir de los recursos con los que cuenta el editor.

En cada libro subyace una idea original que oscila entre las convenciones provenientes de la tradición y la propia creatividad, idea acorde con la hipótesis de la "heterogeneidad para cualquier hecho de producción o consumo" en la cultura, según los planteamientos de Itamar Even-Zohar. ${ }^{13}$ La idea se esboza y, no obstante las estrategias previsivas, las condiciones sociales harán más o menos favorable su recepción en los lectores en su momento, pero también la adquisición sostenida o no de este producto a lo largo del tiempo por parte de los compradores, lo cual genera nuevas y adaptadas ediciones.

Un diseño metodológico en la historia del libro y de la edición tendría en consideración los modos de acceder al conocimiento de las condiciones de negocio a las que el editor está sujeto en su momento, y de aspectos intelectuales como la tradición tipográfica que transforma manuscritos en libros, según del

\footnotetext{
${ }^{12}$ Emmanuël Souchier, "L'image du texte pour une théorie de l'énonciation éditoriale", Les Cahiers de Médiologie 6, núm. 2 (1998): 137-145.

${ }^{13}$ Itamar Even-Zohar, "Factores y dependencias en la cultura. Una revisión de la teoría de los polisistemas", en Teoría de los Polisistemas, coord. y trad. de Montserrat Iglesias Santos (Madrid: Arco Libros, 1999), 39.
} 
tipo que sean, y la generación de una línea, política o filosofía editorial que conjuga arte, oficio, ciencia y tecnología. La idea de sostener una visión holística del libro en una investigación, como la que plantea Robert Darnton, es ambiciosa; no obstante, desde el principio él mostró que un modo de sostenerla es a través de un modelo en el que tengan representación los participantes del concierto que es el libro. Y en el caso de una publicación periódica científica hay aspectos que deben considerarse más allá de los propiamente editoriales, si quiere sostenerse esta visión.

\section{Modelos}

Si un modelo científico es "una copia [...] remedo o símil de objetos o procesos ${ }^{\prime \prime}{ }^{14}$ el reto desde la historia del libro y de la edición es crear una representación del proceso de fabricación de una publicación periódica científica; pero lo es aún más si dicho modelo es capaz de reflejar su puesta en funcionamiento en la comunidad científica (cuyos integrantes comparten teorías y prácticas de una disciplina y medios de comunicación entre sí y con un amplio público) a través del tiempo, es decir, si es transhistórico.

Michael Bhaskar hace algunas aclaraciones de pertinencia en relación con la diferencia entre un modelo científico y un modelo editorial. Cree que, a diferencia de los modelos científicos que "sirven para explicar el mundo" y hacen referencia a "representaciones de cosas", los modelos de edición se dirigen a guiar las acciones, y que quienes los usan en realidad sólo los hacen conscientes o entienden parcialmente, ya que en gran medida están ocultos; en contraste, también, con un modelo de negocios que se establece explícitamente y se define con claridad. Afirma que "los editores tienden a emplear los modelos no para entender el mundo (como los científicos) sino para hacer cosas con él". ${ }^{15}$ Un modelo científico para estudiar una publicación periódica científica permitiría revelar en mayor o menor medida esos modelos editoriales "ocultos" para sus ejecutores, y los modelos de negocio serían sin duda una fuente de gran valor para esta disciplina, aunque normalmente es información confidencial de difícil acceso. La tarea en esta disciplina, al fin y al cabo, es explicar el mundo editorial, lo que daría elementos para un mejor ejercicio a quienes "hacen" la edición.

\footnotetext{
14 José Luis Díaz, "Modelo científico: conceptos y usos", en El modelo en la ciencia y la cultura, coord. de Alfredo López Austin (México: Siglo XXI / UNAM, 2005), 13.

${ }^{15}$ Michael Bhaskar, La máquina de contenido. Hacia una teoría de la edición desde la imprenta hasta la red digital (México: FCE, 2004), 169-170.
} 
Even-Zohar hace también énfasis en la cualidad productiva de los modelos, y para ello da como ejemplos de "actuación de los modelos" el trabajo editorial y la enseñanza de la composición de textos. ${ }^{16} \mathrm{El}$ autor explica los modelos como un conjunto de elementos, reglas y relaciones temporales que, para el caso de un evento o suceso (como la actividad editorial), el productor requiere de un pre-conocimiento que le indique qué hacer y cuándo, a partir de las posiciones de los elementos y del orden o secuencia que debe seguir. ${ }^{17}$ Esto reflejado en un modelo de edición de una publicación periódica científica implica un conocimiento de los productores acerca de las acciones necesarias para generar una publicación periódica científica, y el orden para realizarlas, y aunque no todas estas acciones se hagan en cada proceso, sabrán que algunas son imprescindibles y que sería imposible realizar unas antes que otras, como en un código implícito del "saber hacer" la edición.

El modelo, en cuanto "conjunto de instrucciones" o pautas, debe entenderse como una "cadena abierta y con diversas ramificaciones posibles", y no como una "serie herméticamente cerrada". ${ }^{18} \mathrm{Y}$ es que en la realización de un repertorio, añade Even-Zohar, el productor negocia o hace adecuaciones entre lo conocido (los modelos, el uso de uno o de varios) y la situación específica de realización o características del fenómeno al que se enfrenta, según el "grado de 'deriva'" y el "grado de 'fijeza'."19 No hay una trayectoria predecible, y esta explicación se ajusta a lo que expone Bhaskar en cuanto a la actividad caótica de editar, que precisamente demanda ajustes en cada situación. Por eso, en la teoría de Even-Zohar un producto, en este caso la realización material (publicación periódica) de la actividad de editar, no es simplemente "la realización o actualización de un modelo", sino el resultado de la oscilación entre modelos preestablecidos y la innovación. ${ }^{20}$

Los modelos de edición son difíciles de explicar, según Bhaskar. Su complejidad radica en que no hay modelos puros, sino sólo modelos híbridos en los que, por un lado, subyacen motivaciones vinculadas de algún modo a fines de lucro, aunque no sea de manera explícita; y, por otro, también están implicados factores que van más allá de los intereses económicos ${ }^{21}$ porque, como añade el

\footnotetext{
${ }^{16}$ Even-Zohar, "Factores y dependencias en la cultura...", 37.

17 Ibid., 35.

18 Ibid., 40.

19 Ibid., 39.

20 Ibid., 43.

${ }^{21}$ Bhaskar, La máquina de contenido, 189.
} 
autor, para entender los modelos no se pueden separar "la estética de la política, lo científico de lo económico, ni lo religioso de lo profano". ${ }^{22}$ La edición académica es un tipo de edición en la que, de acuerdo con Bhaskar, más claramente se manifiesta esta aparente dualidad o contradicción que puede darse en un modelo, aunque "el error es creer que las dos cosas estén necesariamente fuera de sintonía". Y cree que por más que nos esforcemos en ver la edición universitaria como carente de fines de lucro, en realidad los modelos en los que se basa se parecen mucho a los de otro tipo de edición que opera con fines de lucro, por el hecho de que ambos pretenden alcanzar metas: "lo que en apariencia no tiene fines de lucro no obstante genera ganancias". ${ }^{23}$

El argumento de la hibridez de los modelos de edición (con o sin fines de lucro) es el que quisiera esgrimir para aclarar que, si bien en el ámbito de la edición académica los autores no esperan obtener ganancias económicas de la venta del producto de sus investigaciones, o incluso en ciertos modelos tengan que pagar para ello, se benefician mediante la obtención de becas o subvenciones de proyectos de investigación, al escalar categorías producto de la evaluación de su actividad.

Se sabe que hay beneficios indirectos, dados en la medida en que la publicación contribuye a elevar el prestigio del autor, a partir del valor de marca de la editorial científica, la fama de un título, el nivel de influencia de los autores que han escrito previamente en la revista, los índices en los que esté y su factor de impacto. El prestigio de los autores publicados nutre, a su vez, el de la revista. De tal modo que el otorgamiento de valor simbólico puede darse en un doble sentido, de la revista al autor y, posteriormente, del autor a la revista, adicionando valor material, por no decir, "financiero". Todo esto es reconocible en el proceso de legitimación de la ciencia, en el que actúa como en un engranaje con el sistema editorial y con otros, como se verá más adelante.

Los autores científicos obtienen ventajas en el marco de la dinámica de los sistemas de la ciencia y de la edición actuales, más otros de carácter simbólico que tienen diversas expresiones a lo largo de la historia. Sin embargo, aun en la edición académica (no comercial) y en la edición universitaria, si bien el objetivo principal o condición de su permanencia puede no ser necesariamente una operación con ganancias, es posible que se obtengan, como lo menciona Bhaskar, lo cual hablaría además de una adecuada planeación estratégica y fi-

\footnotetext{
22 Ibid., 184.

${ }^{23}$ Ibid., 187.
} 
nanciera, y de la posibilidad de publicar más para contribuir al objetivo, que sí es explícito en este caso, de la difusión del conocimiento generado por los investigadores. Ante estas reflexiones, llegué a la conclusión de que para la propuesta de un modelo de edición de contenidos científicos lo mejor es evitar la distinción entre el ámbito de la edición científica comercial y el de la académica (universitaria) o institucional, puesto que se parte de la premisa de que en ambos casos operan modelos de negocio.

\section{Publicar y ciencia}

Sobre el papel de las publicaciones en la ciencia, Niklas Luhmann considera que el sistema científico opera a partir de la distinción de los valores verdadero/falso y "se reproduce por medio de la atribución de comunicaciones a este código". ${ }^{24}$ Distingue además entre los procedimientos de la producción de nuevos conocimientos, que puede regularse mediante métodos científicos, y los procedimientos de la edición de publicaciones que son de otro tipo, pues requieren, más bien, de "una metodología no dirigida a la comunicación". Para él, "sólo bajo la forma de las publicaciones el sistema de la ciencia adquiere capacidad de enlace", ${ }^{25}$ es decir, gracias a las publicaciones y a la posibilidad que generan para que los textos sean citados, se puede adquirir una existencia científica y, en un momento dado, la notoriedad, ${ }^{26}$ además de que sólo a través de la publicación puede hacerse la distinción entre lo que se considerará conocimiento y lo que no, ${ }^{27}$ a partir de una evaluación que ocurre en el sistema científico, en la que sus integrantes operan de manera autónoma.

\footnotetext{
${ }^{24}$ Niklas Luhmann. La ciencia de la sociedad (México: Universidad Iberoamericana / ITESO / Editorial Anthropos, 1996), 222-223. Ángel Luis Sobrino Vegas, en "Las revistas literarias. Una aproximación sistémica", Signa, núm. 23 (2014): 827-841, realiza una propuesta desde una perspectiva sistémica para las revistas literarias que fue un referente para la investigación sobre el Boletín de Ciencias Médicas. Sobrino menciona que dicha perspectiva es representativa en autores como Luhmann, Even-Zohar, Lotman y S. J. Schmidt, 828.

${ }^{25}$ Luhmann, La ciencia de la sociedad, 309-310.

${ }^{26}$ Aspecto que también analiza Pierre Bourdieu, "El campo científico", Redes: Revista de Estudios Sociales de la Ciencia 1, núm. 2 (1994): 129-160, acceso el 27 de marzo de 2021, http://ridaa.unq.edu.ar/handle/20.500.11807/317; al igual que Bruno Maltrás en "Generación y comunicación del conocimiento científico", en Procesamiento de la información científica, coord. de Wilfrid Lancaster y María Pinto (Madrid: Arco Libros, 2001).

${ }^{27}$ Luhmann, La ciencia de la sociedad, 213.
} 
Por su parte, Bruno Maltrás cree que, frente a otro tipo de espacios públicos regulados en el que se exponen resultados de la investigación, es el del "sistema de publicación de la ciencia" el que a la larga prevaleció sobre los otros como espacio de comunicación no sólo oficial, sino legitimador, y por tanto relacionado con la adquisición de autoridad científica y reconocimiento. Expresa además que esto se concreta en el "documento científico", del que los lectores esperan invariablemente la exposición de algo nuevo; ${ }^{28}$ y este último elemento es tan importante que el autor define el sistema de publicación de la ciencia como el lugar donde tiene una concreción "el proceso social que culmina con la generación de nuevo conocimiento científico", ${ }^{29}$ aunque también como ámbito en el que "la ciencia ejerce su autonomía y posibilita las dimensiones de publicidad que son esenciales en su modo de producción y para su propia supervivencia". ${ }^{30}$

Los actores que participan en la discusión a la que Luhmann hace referencia como basada en el código verdadero/falso son los que, de acuerdo con Maltrás, forman la "comunidad científica", y el escenario donde se representa dicha discusión, o los debates científicos, es el "sistema de publicación de la ciencia". ${ }^{31}$ El lector-científico se convierte, a su vez, en autor-científico. ${ }^{32}$

A partir de la idea de la "indisociabilidad de generación y comunicación del conocimiento científico" y de la "publicidad" como "rasgo esencial del propio modo de producción de conocimientos científicos", Maltrás propone entender la ciencia como "un verdadero sistema colectivo de producción de conocimientos, lo que incluye el rechazo a la idea de que la generación del conocimiento científico pueda reducirse a una labor individual", como tampoco lo es, naturalmente, su comunicación, que identifica como "necesariamente un proceso social". La realización de este sujeto colectivo se da en el funcionamiento del sistema de publicación, y sus productos (los documentos científicos) son la materia prima del conocimiento científico". La ciencia es "el producto de un proceso epistémico colectivo autónomo que se basa en la publicidad de los resultados científicos". ${ }^{33}$ Y desde una perspectiva sistémica se entendería la ciencia como un "ámbito de

\footnotetext{
${ }^{28}$ Bruno Maltrás, "Generación y comunicación...", 29.

${ }^{29}$ Ibid., 32.

$30 \mathrm{lbid}$.

${ }^{31}$ Ibid., 21.

${ }^{32}$ Luhmann, La ciencia de la sociedad, 230.

${ }^{33}$ Maltrás, "Generación y comunicación...", 20-22.
} 
actuación social" en cuyo proceso de comunicación individuos y grupos asumen diversos "papeles de actuación". ${ }^{34}$

El "sistema de publicación de la ciencia", según Maltrás, hace referencia también a "los elementos, agentes y pautas que intervienen en la producción de documentos científicos 'oficiales'", en donde los elementos son "los investigadores (en su doble papel de autores y lectores)", además de "los periódicos especializados, sus editores responsables, los revisores anónimos" y "las instituciones científicas que promocionan y mantienen estos periódicos con sus suscripciones". ${ }^{35}$ Por su parte, Arguimón y Jiménez explican que son cuatro los elementos que intervienen en la comunicación científica: "los investigadores o autores de los manuscritos, los editores de las revistas, los asesores que revisan los trabajos y los lectores de los artículos que se publican". ${ }^{36}$

José Antonio Cordón García hace referencia a una "edición científicotécnica", mas no a un "editor científico-técnico", quizá porque prefiere diferenciar el nivel de actuación del especialista científico del nivel de actuación del responsable de las cuestiones de planeación estratégica, financieras, administrativas, de mercadotecnia, comerciales y de distribución, a quien denomina "editor comercial"; también porque tal vez prefiera deslindar al especialista-investigador de las cuestiones que atribuye al editor comercial, de tal manera que separa el ámbito del sistema científico del sistema editorial, que de todas formas considera como "un subsistema o un segmento del sistema global de la ciencia, una parte inseparable y necesaria del mismo". ${ }^{37}$

Esto es comprensible si se entiende el sistema científico como excluyente de una lógica mercantil o de negocios en relación con los productos que pueden contener conocimiento nuevo, a partir de la idea de que los autores ubicados en dicho espacio no esperan, al insertarse en el sistema editorial -por lo menos no en primera instancia-, una retribución económica por la exposición de su conocimiento (en este caso, en forma de textos), sino que están motivados

\footnotetext{
${ }^{34}$ Tal como Sobrino lo hace en el caso de la literatura, Sobrino Vegas, "Las revistas literarias...", 828, 834 .

${ }^{35}$ Maltrás, "Generación y comunicación...", 32, 33.

36 J. M. Argimón Pallas y J. Jiménez Villa, "La comunicación científica: autor, editor, revisor y lector", Atención Primaria. Sociedad Española de Medicina de Familia y Comunitaria 22, núm. 3 (julio de 1998): 186.

37 José Antonio Cordón García, "La edición científico-técnica: balance y perspectivas", en El procesamiento de la información científica, coord. de Wilfrid Lancaster y María Pinto (Madrid: Arco Libros, 2001), 78.
} 
por un beneficio simbólico (en términos de Pierre Bourdieu), en un campo científico donde la lógica es la de la competencia por el reconocimiento de los pares (que son, a su vez, sus competidores), ${ }^{38}$ a diferencia de la lógica del sistema editorial, donde la competencia se da entre entidades editoras por una parte del mercado, a partir de la oferta de sus productos.

Tanto Maltrás como Cordón en sus propuestas sostienen que la producción y comunicación de la ciencia son indisociables, o que el subsistema editorial es inseparable del sistema global de la ciencia; no obstante, se percibe en esta dependencia una subordinación del sistema editorial en relación con el científico. De igual modo, se refleja una visión de la publicación periódica científica como un producto en el que sólo se publica "nuevo conocimiento", cuando es bien sabido que desde que aparecieron las primeras Philosophical Transactions of the Royal Society y Journal de Savants (1665) presentaban otro tipo de contenidos de interés para los lectores practicantes de ciencias.

Desde las perspectivas aquí presentadas, parecería que cuando el punto de vista en una investigación es la ciencia, al estudiarse una publicación periódica se tendría un producto fragmentado, del que se extrae sólo lo que remite a "conocimiento nuevo", pero ¿qué sucede con el resto de sus contenidos, que al final dialogan con todos los elementos de la publicación periódica científica para ofrecer un discurso total?

En su construcción de una historia de la ciencia en México en el siglo XX, Ruy Pérez Tamayo afirma que sólo llamará ciencias "a las actividades primariamente dirigidas a la generación de nuevos conocimientos científicos". Al tratar de las instituciones científicas de la segunda mitad del siglo XIX, advierte que "en su tiempo fueron consideradas como científicas, y aunque es indudable que en algunas de ellas sí generaron nuevos conocimientos, la gran mayoría más bien se dedicó a la recepción y divulgación de la ciencia desarrollada en otros países". Tales apreciaciones se basan en su siguiente definición de ciencia: "es una actividad humana creativa cuyo objetivo es la comprensión de la naturaleza y cuyo resultado es el conocimiento, obtenido por un método científico deductivo y que aspira al máximo consenso entre los expertos relevantes". 39

Si bien todo esto es innegable, como también es válido que desde la historia de la ciencia solamente tengan interés este tipo de contenidos cuando se

\footnotetext{
${ }^{38}$ Véase Bourdieu, "El campo científico".

${ }^{39}$ Ruy Pérez Tamayo, Historia general de la ciencia en México en el siglo XX (México: FCE, 2005), 34 y 44.
} 
estudian publicaciones periódicas (considerando, esto sí, incluso los que fueran una interpretación o literalmente copia del conocimiento proveniente del extranjero), para una visión integral de este objeto de estudio tendrían que considerarse todos sus elementos, incluso aquellos con fines y características no científicas. En México, desde el siglo XVIII y hasta la primera mitad del XX se identifican publicaciones periódicas como el mismo Boletín de Ciencias Médicas, cuyos contenidos son misceláneos en cuanto a géneros (artículo original, traducción, noticia, etc.) y temas. En esos momentos las fronteras entre lo que hoy es claramente una revista de investigación, profesional, de divulgación e incluso una cultural, no estaban bien definidas.

Desde una perspectiva de la historia del libro y de la edición, el criterio de "nuevo conocimiento" para incluir una publicación periódica en el corpus de la literatura científica sería una limitante, ya que muchas agregaron a este tipo de contenido otro que no era nuevo e incluso ni científico. Son producto de un momento previo a la que podría reconocerse como una ciencia académica y al desarrollo de las actividades de investigación en el marco de políticas científicas estructuradas por parte del gobierno. A lo anterior se agrega la desigual evolución de las disciplinas que, en algunos casos, influye en el más temprano o tardío surgimiento de sus revistas. Emilio Delgado afirma al respecto:

Para una mejor comprensión del hecho comunicativo en la ciencia debemos tener presente que existen profundas diferencias en las prácticas de comunicación de los científicos pertenecientes a distintas disciplinas, que éstas-como cualquier hecho histórico- evolucionan con el tiempo, y que se ven condicionadas por factores de orden geográfico, económico, político, social y cultural. ${ }^{40}$

Para la consideración de lo que es una "publicación periódica científica" en la investigación sobre el Boletín de Ciencias Médicas, y en las que le siguieron y que se proponen desde la historia del libro y de la edición, el criterio es aquella cuyos creadores y productores propusieron ante la comunidad de profesionales con una intencionalidad científica, y en la que se encuentra el "artículo científico" como uno de sus géneros, independientemente de su proporción en relación con otro tipo de textos.

${ }^{40}$ Emilio Delgado López-Cózar y Rafael Ruiz Pérez, "La comunicación y edición científica: fundamentos conceptuales" [PDF original del autor], en Homenaje a Isabel de Torres Ramírez: Estudios de documentación dedicados a su memoria (Granada: Universidad de Granada, 2009), 6, acceso el 11 de febrero de 2021, http://eprints.rclis.org/13988/. 
Al caducar la novedad del conocimiento que representaron en un momento dado sus contenidos, estas publicaciones periódicas pasan a constituir parte de un "archivo organizado" en el sistema documental. Aun los considerados "artículos" en los periódicos de medicina del siglo XIX y primera mitad del XX en México responden a criterios científicos en configuración, pues emergen de un ambiente en el que se da una "heterogénea definición de los cánones de cientificidad". ${ }^{41}$

Debe añadirse el hecho de que desde la historia del libro y de la edición invariablemente se considerará como unidad de estudio la publicación periódica y no los textos individualizados, pues se trata de una perspectiva integral en la cual se asume el discurso total de dicho producto que incluye, entre otros, el tipográfico.

\section{Editor y edición científicos}

Si se quiere hacer la propuesta de un modelo que permita entender la edición, es necesario tener claro qué se entiende por ésta, particularmente lo relacionado con la edición científica. En el ámbito del libro antiguo se llamaba "editor" a la persona que financiaba su producción y que, por tanto, podía tener injerencia en la toma de decisiones respecto a las características del producto.

Si bien éste fue el sentido de la palabra "editor" que prevaleció en dicho contexto, a finales del siglo XVIII, en Nueva España, José Antonio Alzate se asume como "editor" para tareas que excedían el ámbito económico, por ejemplo la selección, síntesis y compilación de textos. Con todo y lo anterior, fue hasta el siglo XIX cuando comenzó a entenderse por "editor" la figura que comparte distintas naturalezas que en este ámbito son perfectamente conciliables, por un lado la del empresario y por otro la vinculada con tareas intelectuales, creativas, técnicas, de promoción y difusión en la realización de un proyecto editorial, aunque en muchas de ellas sea sólo el director y no el ejecutor, es decir, quien toma las decisiones.

\footnotetext{
${ }^{41}$ Luz Fernanda Azuela, "El régimen de cientificidad en las publicaciones del último tercio del siglo XIX", en Geografía e Historia Natural: hacia una historia comparada. Estudio a través de Argentina, México, Costa Rica y Paraguay, t. III, coord. de Celina A. Lértora Mendoza (Buenos Aires: Ediciones FEPAl, 2010), 103. La autora plantea además que sólo con la creación de los institutos de investigación a finales del siglo XIX se "abrió paso a la edición de revistas especializadas con lenguajes y contenidos esotéricos, que se alejaron del gran público", 117.
} 
En lo que atañe al editor de publicaciones periódicas científicas, ya en el siglo XX, entre las mediaciones que se dan a través de su figura resaltan, en su función intelectual, la definición de un concepto y línea editoriales. Inicialmente, al surgir en México este tipo de materiales en el siglo XVIII, luego en el XIX, e incluso durante toda la primera mitad del XX, estos productos agruparon información no sólo científica, sino otra de interés para los profesionales. Dada esta multiplicidad de contenidos sería difícil clasificar muchas de estas revistas con categorías actuales como "revista de investigación", "revista técnica" o "revista profesional". La definición y publicación de lineamientos editoriales para los autores, tal como se conocen hoy, se dio de manera muy esporádica durante la primera mitad del siglo XX y sólo se consolidó hasta la segunda mitad. La institucionalización de la ciencia, así como los requerimientos de medición de productividad científica avanzado el siglo XX, brindan el marco para ver involucrado también al editor en el proceso de arbitraje, mediante la selección de revisores o pares (de los autores).

Para Gerardo Kloss Fernández del Castillo, el editor en la actualidad conjuga tres papeles: a) el técnico organizativo, b) el político-cultural y c) el empresarial, ${ }^{42}$ estrategias que se superponen ${ }^{43}$ y derivan en la realización o supervisión de tareas de "naturaleza esencialmente editorial, ya que sólo operan como tales en conjunto y pierden este sentido cuando se realizan separadamente". ${ }^{44}$ Kloss propone un boceto de definición de lo editorial o de la tarea del editor, como sigue: "investigar, planear, seleccionar, organizar, expresar, formalizar, materializar, distribuir, vender, aplicar y evaluar contenidos relevantes para la satisfacción de demandas específicas, poniéndolos en los lugares, momentos, presencias y productos más apropiados para cada caso". 45

Por otro lado, José Martínez de Souza plantea que en todo proceso de edición hay una mente creadora, el autor, una mente rectora, el editor o director intelectual, una mente coordinadora, el coordinador editorial, y un realizador, el productor. ${ }^{46}$ Este autor reconoce también la figura del editor científico, llamado

\footnotetext{
${ }^{42}$ Véase Gerardo Kloss Fernández del Castillo, Entre el oficio y el beneficio: el papel del editor. Práctica social, normatividad y producción editorial (Guadalajara: Editorial Universitaria, 2007), 53-54.

43 lbid., 132.

${ }^{44} \mathrm{lbid} ., 54$.

$45 \mathrm{lbid}$.

${ }^{46}$ José Martínez de Sousa, Manual de edición y autoedición (Madrid: Ediciones Pirámide, 2004), 57.
} 
propiamente de esta manera a partir, aproximadamente, de mediados del siglo $X X$, según indica, en la que recae el compromiso de responder sensiblemente a las necesidades de socialización del conocimiento de la comunidad científica en cada disciplina, de establecer la red de especialistas responsables de la revisión por pares y de asegurar el cumplimiento de normas de publicación, en conformidad con las prácticas científicas internacionales de publicación.

Martínez de Souza refiere además que en los años 50 del siglo XX surgió la noción de "edición científica" aplicada a trabajos publicados en revistas y editoriales científicas, a partir de que las editoriales hemerológicas comenzaron a recibir una cantidad abrumadora de trabajos de este tipo, mal escritos y poco legibles. Según el autor, estas circunstancias forzaron a este tipo de editoriales a buscar una guía de unificación de criterios para los escritos científicos, y así fueron surgiendo iniciativas para la normalización en este campo. ${ }^{47}$

Cordón García, por su parte, hace algunos señalamientos en cuanto al editor de libros científicos, a quien adjudica un papel "puramente técnico" que correspondería a la aprobación de la impresión de un texto, y posteriormente la organización y control de su distribución, ${ }^{48}$ esto, en el marco de lo que denomina la "edición científico-técnica", que en cada país la constituyen: "todas aquellas obras de información, consulta y divulgación, cuya finalidad es la de transmitir conocimientos organizados y sistematizados en cualquier parcela del saber y en cualquier tipo de soporte, así como por todas aquellas estructuras, empresariales, legislativas, políticas, económicas y culturales que posibilitan su distribución y consumo". ${ }^{49}$

En el circuito científico que propone Cordón García parece no haber un mayor involucramiento del editor respecto a los contenidos. Para este autor, quien hace una revisión y aprobación es el especialista que participa del "micromedio científico" y que cuenta con el aval institucional desde el sistema científico para ejercer un control de calidad intrínseco. En contraste, los "sistemas de control de calidad extrínsecos del micromedio editorial" consisten solamente en tareas de difusión y consumo..$^{50}$ No existe una figura que se denomine "editor científico" desde la propuesta de Cordón García, sino un "responsable científico" de textos y colecciones.

\footnotetext{
47 Ibid., 90-91.

${ }^{48}$ Cordón García, "La edición científico-técnica...", 69.

${ }^{49}$ Ibid., 68.

${ }^{50} \mathrm{Ibid}$., 81.
} 
En esta concepción, el editor queda relegado a las tareas técnicas, comerciales y distribucionales del sistema de la edición científico-técnica, lo que en los términos de Kloss correspondería a los papeles técnico-organizativo y, en todo caso, empresarial, mas no el político-cultural. A partir de lo anterior podría surgir el cuestionamiento acerca de si la decisión de que un texto se publique (hacerlo público) o no, o de elegir uno entre varios por parte de quienes integran el "sistema de control de calidad extrínseco del micromedio editorial", implica un tipo de valoración, no en el sentido en que la hacen los "pares" científicos, sino, por ejemplo, en cuanto a su mayor o menor adecuación a una línea editorial, o del que aporte una mayor en cuanto al criterio de "originalidad".

A partir de las reflexiones de Pierre Bourdieu sobre el campo intelectual, el editor es uno de los agentes del sistema de producción intelectual que se desarrolla en este campo, entendido como sistema de relaciones, donde también operan las instancias de consagración y difusión cultural, como las casas editoras y las asociaciones científicas, en una lógica de competencia por la legitimidad cultural. ${ }^{51}$ Aunque para el caso particular de su desarrollo de la lógica del funcionamiento del campo de producción simbólica, que es el campo científico, este autor no aborda el tema del "editor", sí menciona que las revistas científicas constituyen, junto con otras instancias de consagración como las academias y los premios, un instrumento de difusión de la ciencia oficial, por medio del cual opera la censura de "producciones heréticas" mediante su rechazo o líneas editoriales excluyentes, en el orden de las estrategias de conservación que pueden aplicar los "dominantes" en el sistema científico, frente a los "pretendientes".52

Puede decirse que el editor opera en un campo intelectual donde se pone en juego la legitimidad para los autores, de uno u otro sistema, a partir del reconocimiento de la originalidad de su trabajo por parte de otros (ya sean pares, miembros de comités editoriales y de lectura, etc.). Realiza, pues, un trabajo de mediación en el proceso de oficialización de la ciencia. De este modo, las publicaciones y editoriales científicas se convierten en instancias de consagración.

Para saber cómo llegó a conformarse la identidad de lo que hoy se denomina "editor científico" será necesario identificar, en la diacronía, las prácticas y representaciones derivadas de su quehacer como profesional de la edición, como parte de una colectividad (otros editores) y en relación con las institucio-

\footnotetext{
${ }^{51}$ Pierre Bourdieu, Campo de poder, campo intelectual. Itinerario de un concepto (Buenos Aires: Ed. Montressor, 2002), 11 y 14.

52 Bourdieu, "El campo científico", 144-145.
} 
nes u organizaciones que lo legitiman ante la sociedad. Principalmente cuando se carece de archivos editoriales en el estudio de la edición científica, la fuente hemerográfica es de enorme valor en cuanto a lo que puede aportar para analizar, de manera sincrónica, qué es un editor a partir del contexto local del cual surge, del momento y de las condiciones en que desarrolla su actividad. De este tipo de fuentes pueden recuperarse también los usos de la palabra "editor", para el trabajo terminológico, y la búsqueda de las funciones con las que se le relaciona.

En lo que respecta a la parte conceptual y de funciones en la elaboración del Boletín de Ciencias Médicas, expuesta ampliamente en su biografía editorial, puede decirse aquí brevemente que se identificó en algunos textos de Manuel S. Soriano la falta de una autodenominación de su persona como "editor". Tampoco en el organigrama o directorio aparece la palabra "editor", sino otras como "director" y "administrador", "secretario de redacción" y "colaborador", que podrían dar a un lector contemporáneo más la idea de una organización periodística al estilo de la prensa política o cultural, o del periódico diario.

En los Anales de la Asociación Larrey (1875-1876) se consigna al doctor Soriano con el crédito de "comisión de redacción y estilo", aunque aparece también, junto a su dirección y nombre, "redacción y administración". De 1886 a 1915 fue el "administrador" de la Gaceta Médica de México, y finalmente "director" del Boletín, aunque presidía también la comisión de redacción y estilo. No obstante, llama la atención que en las páginas de esta última publicación otros aludan al doctor Soriano y a su hijo Manuel como "redactores del Boletín" ${ }^{53} \mathrm{y}$ "editores". ${ }^{54}$

Se entiende que, a pesar de que en los créditos de carátula Manuel F. Soriano se reconoce sólo como "administrador", hay una percepción de su trabajo como relacionado con el manejo de los contenidos -que muy probablemente compartía con su padre-, pero en diferente nivel. Otro comentario en el Boletín parece confirmar esta percepción, al hacer referencia indirecta a que

53 "Un elogio que honra al 'Boletín de Ciencias Médicas'", Boletín de Ciencias Médicas, t. III, núm. 4 (octubre de 1912): 147.

54 "Y que los editores de esta publicación, que tanto empeño han mostrado por hacer de ella un periódico científico, útil y moderno, se vean más alentados a su loable empresa y al terminar tú se sientan ampliamente satisfechos". R. E. C. [Ricardo E. Cicero], "¡Año Nuevo...! ¡Año Nuevo...!”, Boletín de Ciencias Médicas, t. IV, núm. 7 (enero de 1914): 290. También en la siguiente cita: "Sostiene al 'BOLETíN' la incansable y convicta dedicación de su editor y administrador, el Sr. Manuel F. Soriano, jr.". Gonzalo Castañeda, "Funciones del periodismo médico", ibid., núm. 1 (julio de 1913): 3. 
la publicación cuenta con más de un editor: "creyendo con fundamento, sus editores que las publicaciones periódicas y especialmente las científicas son el mejor reflejo de la vida intelectual de un pueblo".55 Éste es sólo el caso de una publicación periódica en un tema que merece ampliarse a muchos más títulos, para una historia de la edición científica.

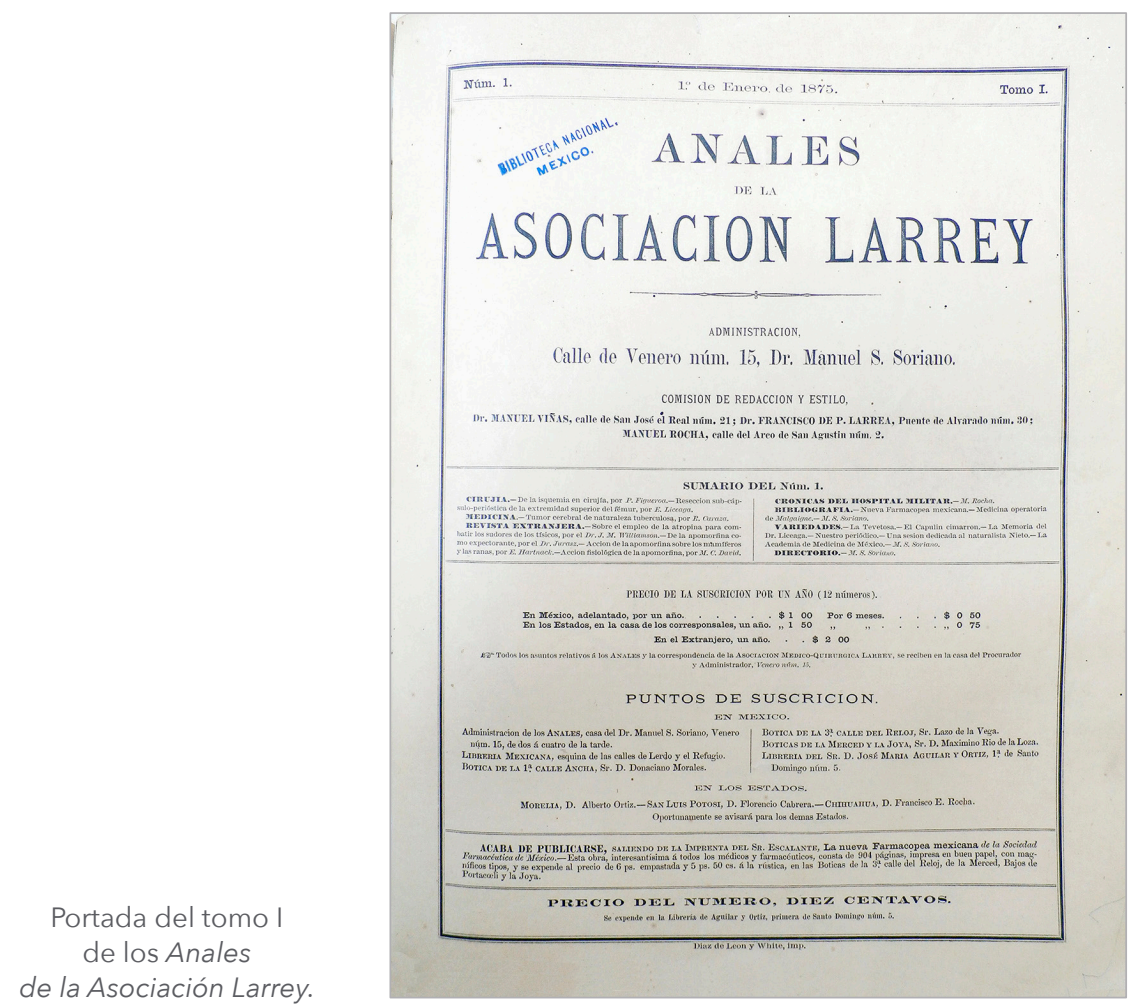

\section{Sistemas en torno a la publicación periódica científica}

El producto material del sistema de publicación de la ciencia constituido en archivo organizado, con las colecciones de volúmenes, lo forman la totalidad de los contenidos de cada número, no solamente las contribuciones de co-

\footnotetext{
${ }^{55}$ Pruneda, "Un año más", Boletín de Ciencias Médicas, t. V, núm. 1 (julio de 1914): 1.
} 
nocimiento de los científicos, sino todo lo que en su momento la comunidad científica consideró necesario comunicar a los profesionales de las ciencias. A partir de las aportaciones multidisciplinarias sobre la publicación en la ciencia y la edición científica, al igual que de la idea de integralidad de la publicación periódica desde la interdisciplinaria historia del libro, se propone la idea de un ecosistema de la publicación periódica científica en el núcleo, y en cuya órbita se mueven cuatro sistemas: sistema editorial, sistema científico, sistema hemerográfico y sistema documental y de información, con elementos internos a su vez, como actores o agentes (y actividades) cuyas intervenciones en distintos momentos los acercan a los lectores. Estos son los presupuestos para el desarrollo de modelos destinados a estudiar las publicaciones periódicas científicas.

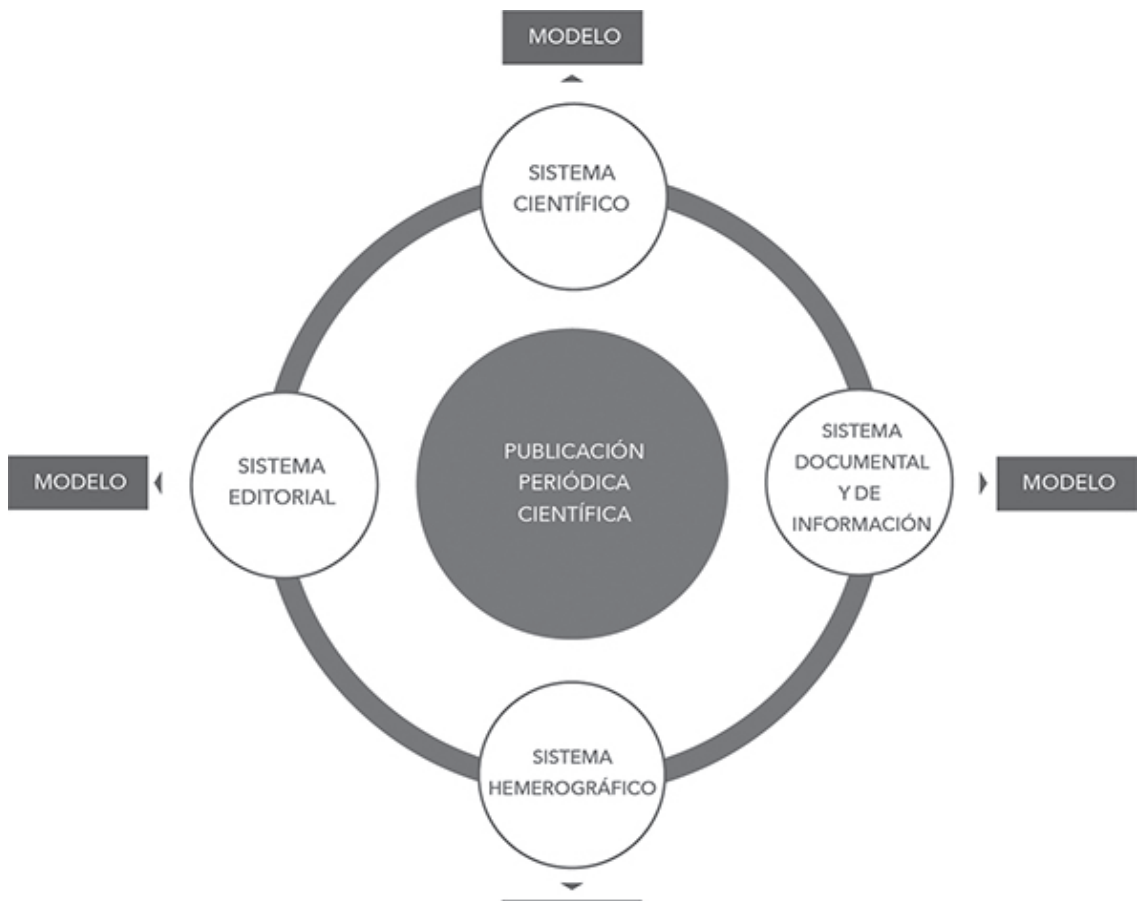

MODELO

Ecosistema para una visión integral de la publicación periódica científica y la producción de modelos para su estudio. 


\section{Sistema científico}

Es donde se produce (mediante el método científico) y se expone el conocimiento (con base de metodologías para la escritura especializada que incluye cuestiones de estilo, estructura y formato). Es también donde se inicia el proceso de oficialización científica de los contenidos para las revistas, a través de un mecanismo de evaluación y aprobación por parte de revisores (árbitros y pares), y en el que la reputación y el reconocimiento de los científicos se ponen en juego.

El investigador participa en el sistema científico como productor de conocimiento, pero entra al sistema editorial con el producto de la exposición de ese conocimiento, el "documento científico". En el caso de las revistas especializadas de hoy, éste se encauza básicamente en el género del artículo.

Puede pensarse en espacios físicos, tangibles, en los que se realizan todas estas tareas, y que corresponden a la infraestructura que las instancias públicas o privadas proporcionan a los investigadores: cubículos, bibliotecas, museos y laboratorios, entre otros. La propuesta de Bruno Maltrás revisada aquí brinda elementos para un modelo de sistema científico que gira alrededor de una publicación periódica.

\section{Sistema hemerográfico}

Para la inserción en este sistema, el criterio que prevalece es el de la intención científica dada a una publicación periódica por parte de los actores del sistema científico en el momento de su producción. Se incluirá en este sistema todo material periódico, independientemente de su tecnología de producción y reproducción, que en su momento se creó en respuesta a las necesidades de publicidad del conocimiento que genera la comunidad científica. ${ }^{56}$

Se excluyen consideraciones como la vigencia (u obsolescencia) de contenidos así como la inclusión de géneros textuales adicionales al artículo de investigación, ajenos a los productos de la actividad científica, o incluso una considerable cantidad de publicidad. De igual modo, será indiferente su calidad en el cuidado de la edición, en su diseño y la de los materiales de que está hecha. Deja fuera también la consideración de lo relativo a las identificaciones de tipo legal y comercial que posea y que, como todo lo anterior, responde a las prácticas y exigencias de un contexto histórico determinado.

56 "La comunidad científica es el espacio en el que se crea el conocimiento científico; no es una mera reunión o una red de personas que comparten su dedicación a la misma actividad y los frutos de su trabajo, sino un verdadero sujeto colectivo productor de nuevos conocimientos contrastados". Maltrás, "Generación y comunicación...", 25. 
En este último aspecto se pueden identificar variaciones que van desde la exhibición simple de los datos de la imprenta donde se realizó, del responsable de su elaboración y los precios, hasta la presencia de elementos como el ISSN (siglas en inglés de International Standard Serial Number, que en español significa Número Internacional Normalizado para Publicaciones Periódicas), el código de barras y el DOI (Digital Object Identifier), para la identificación particular del artículo electrónico en una revista.

A partir de todos estos criterios se podrán incluir, dentro del universo de estudio, las publicaciones periódicas que en su momento fueron consideradas científicas, en vez de sólo aquéllas que, según el criterio actual, publican nuevo conocimiento, bajo los estatutos de su validación por parte del sistema de revisión por pares o arbitraje científico. Se privilegian aquí perspectivas como las de la historia de la edición y la historia de la prensa, al observar las revistas científicas en su evolución, pero también insertadas dentro del sistema científico en su relación con todo el medio editorial que genera también otro tipo de revistas (como las literarias) y de publicaciones (libros), y en el que algunos de sus actores tienen participaciones diversificadas (autores, traductores, editores, etc.) en unas y en otras. Es de este modo como también se hará ineludible la tarea de abordar este objeto de estudio en todos sus componentes (textuales, estructurales y físicos) que manifiestan su naturaleza periódica.

En concreto, este sistema contribuye a la historia de la edición porque busca identificar las continuidades y discontinuidades en las prácticas de la edición científica a lo largo del tiempo, y en cuanto a que busca la relación de dichas prácticas con las de otro tipo de revistas, en su modo de concebirse, su estructura, su materialización, e incluso en los géneros y formas textuales. Los historiadores de la ciencia y otros, por ejemplo los historiadores de la literatura, encontrarán también otro tipo de aportaciones al tomar esta categoría de análisis que es el "sistema hemerográfico".

Desde mi punto de vista, la más sólida propuesta de los que yo consideraría elementos de un sistema hemerográfico se encuentra en la obra Tiempo, materia y texto. Una reflexión sobre la revista literaria, de Rafael Osuna. El autor propone basar el estudio de las revistas en "unidades de significación" (título, formato, secciones, tiraje, firmas, sumario, tipos de letra, géneros, lema, grupos, etc.) ubicadas en siete tipos de discursos: mercantil, publicitario, identificador, literario, social, artístico y tipográfico. ${ }^{57}$

57 Véase Rafael Osuna, Tiempo, materia y texto. Una reflexión sobre la revista literaria (Kassel: Edition Reichenberger, 1998). 


\section{Sistema documental y de información}

Podría decirse que, tomando como referencia el modelo de Thomas Adams y Nicholas Barker para el estudio del libro, ${ }^{58}$ mientras que en el sistema editorial se ubicarían las acciones de publicación, elaboración y distribución, el sistema documental y de información daría pie a las de recepción y supervivencia, la primera en cuanto al interés por medir el impacto de las revistas científicas, y la segunda en cuanto a las acciones encaminadas hacia su organización y conservación. Y aunque no es todo lo que cabe en este sistema, de inicio permite poner énfasis en que para el estudio de una publicación periódica científica desde la historia de la edición, conviene separar las tareas que absorben las editoriales de aquéllas que competen a las bibliotecas, aspecto que está hoy en debate.

La "recepción" se relaciona con los lectores y, por tanto, opera más allá del sistema documental y de información, para tener su repercusión final en el sistema científico. Una de las manifestaciones de la recepción del nuevo conocimiento son las citas que los autores incorporan, y que son cuantificables en el sistema documental y de información.

La identificación y conteo de citas puede ser determinante en la imagen más o menos positiva que una revista pueda tener en términos de su atractivo para publicar en ella, a partir de parámetros como su factor de impacto; $y$, a su vez, esta imagen de la revista contribuye en la reputación que puede darle al investigador que ha publicado en ella. Aunque no es sólo éste el factor determinante en la adquisición de prestigio por parte del investigador, sí es uno de los que ponen en juego su posición en la comunidad científica.

En este sistema hay un reconocimiento de la literatura científica como el "producto material" del sistema de publicación de la ciencia que, de acuerdo con Bruno Maltrás, se presenta "como un enorme depósito de las contribuciones públicas de los investigadores a lo largo de varios siglos. Las colecciones de las publicaciones científicas periódicas, con su sistemática ordenación en números y volúmenes y su elevada especialización temática es un modelo de archivo organizado que se construye con el tiempo".59

\footnotetext{
58 Thomas R. Adams y Nicholas Barker, "A New Model for the Study of the Book", en A Potencie of Life: Books in Society. The Clark Lectures, 1986-1987, ed. de Nicholas Barker (Londres: The British Library, 1993), 5-43.

${ }^{59}$ Maltrás, "Generación y comunicación...", 35.
} 
La revista científica es concebida en este sistema como un objeto susceptible de clasificación, descripción, ordenación, resguardo y preservación, todo lo cual se relaciona con las labores realizadas en las bibliotecas y hemerotecas, a partir de los conocimientos que aportan la bibliotecología y las ciencias de la información. Desde estas disciplinas, una revista es considerada "documento".

Como archivo organizado, las publicaciones periódicas se encuentran en bibliotecas, hemerotecas, sitios de Internet o bases de datos que, con su potencial diseminador, al hacerlas accesibles para su consulta, crean posibilidades de que sus contenidos científicos multipliquen el conocimiento histórico o de actualidad. En dichos lugares de difusión se busca, además, la conservación y preservación de los productos hemerográficos como materiales históricos, organizados en volúmenes, encuadernados cuando son impresos, y con fortuna digitalizados.

En el caso de los materiales digitales el tema de los metadatos es actualmente fundamental para la recuperabilidad y trascendencia de la información en el tiempo, no sólo en términos de sus contenidos, sino de las referencias en los catálogos. La tecnología en el procesamiento de la información estrecha los lazos entre el sistema editorial y el sistema documental, según menciona Cordón García, lo que se pone en evidencia en su articulación de labores, cuando la información formal y conceptual de las revistas queda sujeta "a complejos y estrechos procesos de tratamiento y análisis documental que facilitan su posterior recuperación".60

\section{Sistema editoria| ${ }^{61}$}

En él tienen lugar las mediaciones orientadas hacia la transformación tipográfica, a través del diseño y el aval científico de textos que, como parte del total de un producto con una identidad editorial propia encabezada por un título, pasa al resto de los sistemas. No sólo la originalidad de los contenidos de las revistas en términos de su posibilidad de impacto en la comunidad científica reflejado en las citas, sino su diseño y formato, independientemente de la tecnología impresa o digital, pueden influir en el mayor o menor estatus que la publicación periódica adquiere en los sistemas científico y documental (valor simbólico), y en los lectores en busca de información.

\footnotetext{
${ }^{60}$ Cordón García, "La edición científico-técnica...", 81.

${ }^{61}$ Que Cordón García concibe como segmento inseparable y necesario del sistema global de la ciencia, ibid., 78.
} 
Cambios marcados por la tecnología, en este caso digital, como la automatización de los procesos de gestión editorial y las tendencias de accesibilidad abierta de las revistas en Internet, son transformaciones que exigen la adaptación y la actualización de conocimientos (profesionalización) constante por parte de los integrantes de este sistema. Todas estas evoluciones y revoluciones, como la necesidad de acelerar aún más el rimo de publicación y la accesibilidad de artículos en un momento como el actual de la pandemia por covid-19, se toman en cuenta para el desarrollo de modelos para el estudio de una publicación periódica científica.
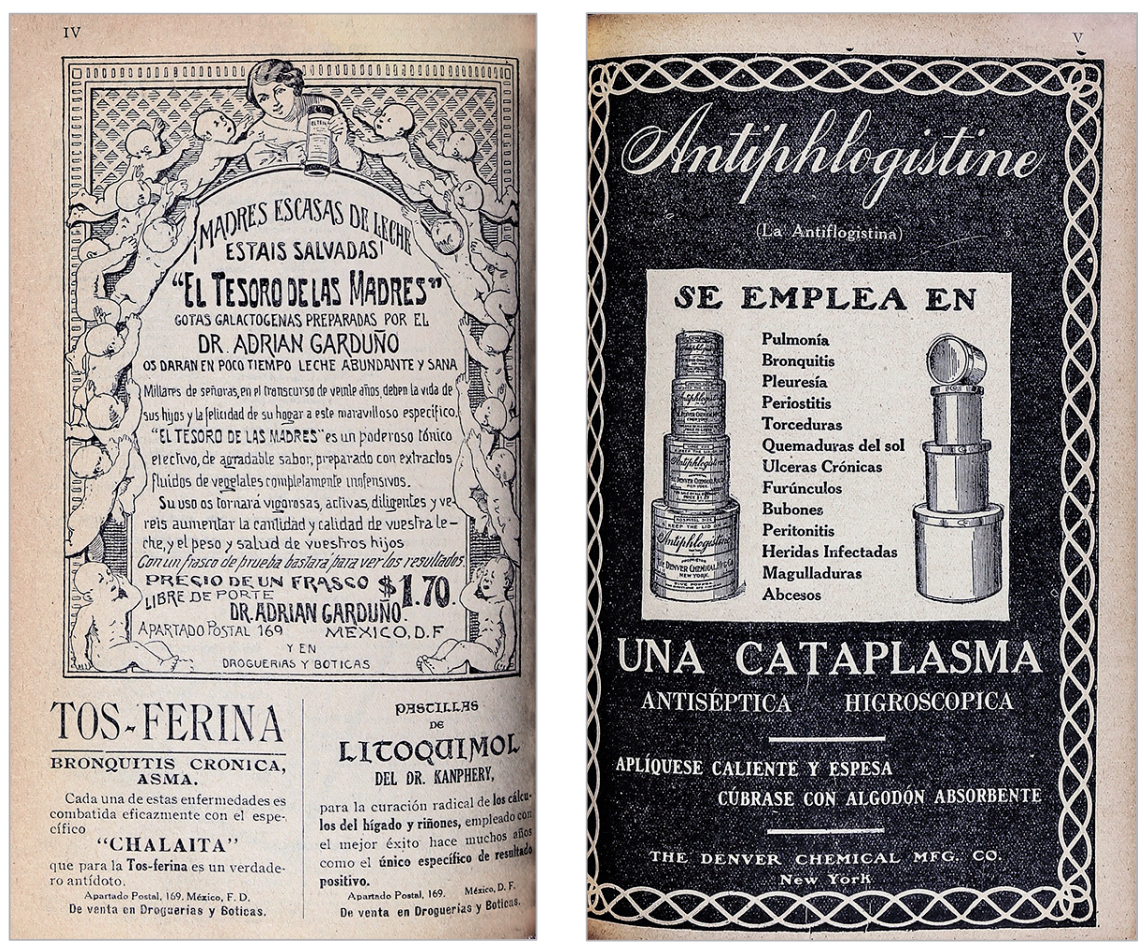

Publicidad en tomo misceláneo del Boletín de Ciencias Médicas. 


\section{Conclusiones}

Con los temas planteados se ha respondido de algún modo a la pregunta que se hizo Robert Darnton al pensar su circuito de comunicación, acerca de cómo un libro se convierte en un libro, y a la idea de Leslie Howsam en el sentido de cómo un libro le sucede a los que lo crean, difunden, leen, compran y resguardan. Con ello también se invita a la creación de modelos a partir de cada uno de los sistemas expuestos que unan las perspectivas de quienes practican las disciplinas que estudian las publicaciones periódicas científicas, pero también de quienes actualmente las hacen. A pesar de las limitaciones de un modelo científico en cuanto a que nunca logrará convertirse en una perfecta analogía u homología con un proceso, ${ }^{62}$ proporciona una opción para el estudio de una publicación periódica científica y, como herramienta metodológica, tiene el potencial de guiar investigaciones interdisciplinarias.

La propuesta de un modelo de edición que se originó al construir una historia de la edición del Boletín de Ciencias Médicas se presentará una vez que cuente con el debido fundamento dado por el estudio de muchas más publicaciones periódicas, de todas las áreas del conocimiento. Un modelo de esta naturaleza servirá para poner énfasis en la consideración de todos los componentes de la publicación periódica científica, es decir, para verla no sólo como "texto escrito" y "transacción cultural", sino en calidad de "objeto material", aspectos que en su conjunto conforman el todo del libro cuando le sucede a quienes lo crean y a quienes entran en contacto con él en las distintas etapas de su vida.

En esta revisión de algunas aportaciones teóricas y conceptuales para presentar un ecosistema de la publicación periódica se coordinan los aportes de varias disciplinas con enfoques de acuerdo con su principal interés como la ciencia, la edición, la prensa o la literatura. Esta propuesta ofrece la posibilidad de mantener una visión integral de la publicación periódica científica en las investigaciones, a pesar de que sólo se le estudie desde uno de los sistemas. El tipo de estudios basados en una visión integral puede dar las bases, asimismo, para una teoría de la publicación periódica y para reflexiones sobre las prácticas actuales de la edición científica que puedan contribuir a la mejora de sus prácticas relacionadas no sólo con una difusión más eficaz, sino con su preservación para la memoria documental y editorial de la ciencia.

${ }^{62}$ Díaz, "Modelo científico: conceptos y usos", 13. 


\section{Referencias}

Adams, Thomas R. y Nicholas Barker. "A New Model for the Study of the Book". En A Potencie of Life: Books in Society. The Clark Lectures, 1986-1987. Edición de Nicholas Barker, 5-43. Londres: The British Library, 1993.

Argimón Pallas, J. M. y J. Jiménez Villa. "La comunicación científica: autor, editor, revisor y lector". Atención Primaria. Sociedad Española de Medicina de Familia y Comunitaria 22, núm. 3 (julio de 1998): 186-187.

Azuela, Luz Fernanda. "El régimen de cientificidad en las publicaciones del último tercio del siglo XIX". En Geografía e Historia Natural: hacia una historia comparada. Estudio a través de Argentina, México, Costa Rica y Paraguay. Tomo III. Coordinación de Celina A. Lértora Mendoza, 103-118. Buenos Aires: Ediciones FEPAl, 2010.

Bhaskar, Michael. La máquina de contenido. Hacia una teoría de la edición desde la imprenta hasta la red digital. Traducción de Ricardo Martín Rubio Ruiz. Colección Libros sobre Libros. México: Fondo de Cultura Económica, 2004.

Boletín de Ciencias Médicas. Tomos III, IV y V. México: Imprenta Santiago Galas. Ejemplares de la Hemeroteca Nacional de México.

Boletín de Ciencias Médicas. Sistema de Índices de la Hemeroteca Nacional de México (Sihena). https://sihena.iib.unam.mx/.

Bourdieu, Pierre. "El campo científico". Redes: Revista de Estudios Sociales de la Ciencia 1, núm. 2 (1994): 129-160. Disponible en RIDAA-UNO Repositorio Institucional Digital de Acceso Abierto de la Universidad Nacional de Quilmes. Acceso el 27 de abril de 2021. http://ridaa.unq.edu.ar/handle/ 20.500.11807/317.

Bourdieu, Pierre. Campo de poder, campo intelectual. Itinerario de un concepto. Buenos Aires: Ed. Montressor, 2002.

Cordón García, José Antonio. "La edición científico-técnica: balance y perspectivas". En El procesamiento de la información científica. Coordinación de Wilfrid Lancaster y María Pinto, 68-99. Madrid: Arco Libros, 2001.

Darnton, Robert. "What Is the History of Books?". Daedalus 111, núm. 3, Representations and Realities (verano de 1982): 65-83. Acceso el 27 de abril de 2021. http://www.jstor.org/stable/20024803.

Delgado López-Cózar, Emilio y Rafael Ruiz Pérez. "La comunicación y edición científica: fundamentos conceptuales" [PDF original del autor]. En Homenaje a Isabel de Torres Ramírez: Estudios de documentación dedicados a su 
memoria, 131-150 [1-16 del PDF]. Granada: Universidad de Granada, 2009. Acceso el 11 de febrero de 2021. http://eprints.rclis.org/13988/.

Díaz, José Luis. "Modelo científico: conceptos y usos". En El modelo en la ciencia y la cultura. Coordinación de Alfredo López Austin, 11-28. México: Siglo XXI / Universidad Nacional Autónoma de México, 2005.

Even-Zohar, Itamar. "Factores y dependencias en la cultura. Una revisión de la teoría de los polisistemas". En Teoría de los Polisistemas. Coordinación y traducción de Montserrat Iglesias Santos, 23-52. Madrid: Arco Libros, 1999.

Frasca-Spada, Marina y Nick Jardine, editores. Books and the Sciences in History. Cambridge, UK: Cambridge University Press, 2000.

Howsam, Leslie. Old Books \& New Histories: An Orientation to Studies in Book and Print Culture. Toronto: University of Toronto Press, 2006.

Jovanovic, Franck, Viera Rebolledo-Dhuin y Norbert Verdier. "Histoire des sciences et histoire de l'édition: de quelle manière peuvent-elles se compléter?". Philosophia Scientiæ 22, núm. 1 (2018): 3-22. Acceso el 27 de marzo de 2021. http://journals.openedition.org/.

Kloss Fernández del Castillo, Gerardo. Entre el oficio y el beneficio: el papel del editor. Práctica social, normatividad y producción editorial. Guadalajara: Editorial Universitaria, 2007.

Luhmann, Niklas. La ciencia de la sociedad. Traducción de Silvia Pappe, Brunhilde Erker y Luis Felipe Segura, bajo la dirección de Javier Torres Nafarrate. México: Universidad Iberoamericana / Instituto Tecnológico y de Estudios Superiores de Occidente / Editorial Anthropos, 1996.

Maltrás, Bruno. "Generación y comunicación del conocimiento científico". En Procesamiento de la información científica. Coordinación de Wilfrid Lancaster y María Pinto, 19-40. Madrid: Arco Libros, 2001.

Martínez de Souza, José. Manual de edición y autoedición. Madrid: Ediciones Pirámide, 2004.

Osuna, Rafael. Tiempo, materia y texto. Una reflexión sobre la revista literaria. Kassel: Edition Reichenberger, 1998.

Pérez Tamayo, Ruy. Historia general de la ciencia en México en el siglo XX. México: Fondo de Cultura Económica, 2005.

Reyes Gómez, Fermín de los. "El libro moderno desde la bibliografía material y la biblioteconomía". Ayer 58, núm. 2 (2005): 35-56.

Rodríguez Kuri, Ariel. "El año cero: el Ayuntamiento de México y las facciones revolucionarias (agosto 1914 - agosto 1915)". En Ciudad de México: Instituciones, actores sociales y conflicto político, 1774-1931. Compilación de 
Carlos Illades y Ariel Rodríguez Kuri, 191-220. México: El Colegio de Michoacán / Universidad Autónoma Metropolitana, 1996.

Rodríguez Kuri, Ariel. Historia del desasosiego. La Revolución en la Ciudad de México, 1911-1922. México: El Colegio de México, 2010.

Sobrino Vegas, Ángel Luis. "Las revistas literarias. Una aproximación sistémica". Signa, núm. 23 (2014): 827-841.

Soriano, Manuel S. "A la grata memoria de los Doctores". Boletín de Ciencias Médicas 6, núm. 6 (diciembre de 1915): 161.

Souchier, Emmanuël. "L'image du texte pour une théorie de l'énonciation éditoriale". Les Cahiers de Médiologie 6, núm. 2 (1998): 137-145.

Valdez Garza, Dalia. La Gazeta de Literatura de México (1788-1795) como periódico libro. Estudio bibliográfico. Ciudad de México: Universidad Nacional Autónoma de México, Instituto de Investigaciones Bibliográficas, Biblioteca Nacional de México, Hemeroteca Nacional de México / Instituto Tecnológico y de Estudios Superiores de Monterrey / Historiadores de las Ciencias y las Humanidades, A. C., 2020.

Valdez Garza, Dalia. Libros y lectores en la Gazeta de Literatura de México (17881795) de José Antonio Alzate. México: Bonilla Artigas Editores / Instituto Tecnológico y de Estudios Superiores de Monterrey, 2014. 